\title{
LA COORDINACIÓN DE LAS POLÍTICAS SOCIALES Y DE EMPLEO EN EL VÓRTICE DE LA GOBERNANZA ECONÓMICA EUROPEA
}

\author{
NORA MARÍA MARTÍNEZ YÁÑEZ
}

\author{
Revista de Derecho Comunitario Europeo \\ ISSN-L 1 138-4026, núm. 52, Madrid, septiembre/diciembre (2015), pp. 949-984 \\ http://dx.doi.org/10.18042/cepc/rdce.52.04 \\ Cómo citar/Citation \\ Martínez Yáñez, N. M. (2015). La coordinación de las políticas sociales \\ y de empleo en el vórtice de la gobernanza económica europea. \\ Revista de Derecho Comunitario Europeo, 52, 949-984. \\ doi: http://dx.doi.org/10.18042/cepc/rdce.52.04
}

\section{Resumen}

La reforma del marco jurídico de la gobernanza económica ha hecho aflorar bajo una nueva perspectiva la irresuelta tensión entre el contenido económico y social del proyecto europeo. La fuerza expansiva de la competencia de coordinación de las políticas económicas ha alterado el modo de ejecución de las competencias de coordinación de las políticas sociales y de empleo y sus interrelaciones. La finalidad de este trabajo es analizar el modo en que las reformas han contribuido a la pérdida de identidad de la coordinación de las políticas sociales y de empleo, y a su consiguiente absorción en la esfera económica, para concluir con una breve reflexión acerca del futuro mediato de estas competencias.

\section{Palabras clave}

Gobernanza económica europea; competencias; políticas sociales; políticas de empleo; coordinación.

1 Profesora contratada doctora de Derecho del Trabajo y de la Seguridad Social, Departamento de Derecho Público Especial, Universidad de Vigo. nora@uvigo. es. Este trabajo forma parte del Proyecto de Investigación «Los instrumentos de protección social privada en la gestión del cambio laboral», financiado por el Ministerio de Economía y Competitividad, DER2014-52549-C4-2-R. 


\title{
SOCIAL POLICY AND EMPLOYMENT COORDINATION IN THE VORTEX OF THE EUROPEAN ECONOMIC GOVERNANCE
}

\begin{abstract}
The reform of the legal framework of Economic Governance has made emerge in a new light the unresolved tension between economic and social content of the European project. The expansive force of economic policy coordination has altered the way of implementation of the social and employment coordination competences and their interrelationships. The aim of this paper is to analyze the way in which the reforms have contributed to the loss of identity of the social and employment coordination, and its subsequent absorption into the economic sphere, to conclude with a brief reflection about the immediate future of these competences.
\end{abstract}

Key words

European economic governance; competences; social policy; employment policy; coordination.

\section{COORDINATION DE LA POLITIQUE SOCIALE ET EMPLOI DANS LE TOURBILLON DE LA GOUVERNANCE ECONOMIQUE EUROPEENNE}

\section{Résumé}

La réforme du cadre juridique de la gouvernance économique a fait émerger dans une nouvelle lumière la tension non résolue entre le contenu économique et sociale du projet européen. La force expansive de la coordination des politiques économiques a modifié la façon dont la mise en œuvre des tâches de coordination des politiques sociales et de l'emploi et de leurs interrelations. Le but de cet article est d'analyser la manière dont les réformes ont contribué à la perte d'identité de la coordination des politiques sociales et d'emploi, et son absorption ultérieure dans la sphère économique, de conclure par une brève réflexion sur l'avenir immédiat de ces compétences.

\section{Mots clés}

Gouvernance économique européenne; compétences; politique sociale; politiques de l'emploi; coordination. 


\section{SUMARIO}

I. INTRODUCCIÓN. II. LA COORDINACIÓN DE LAS POLÍTICAS ECONÓMICAS, SOCIALES Y DE EMPLEO ANTES DE LA CRISIS: 1. Algunas similitudes y varias diferencias entre las competencias de coordinación. 2. La puesta en práctica de las competencias de coordinación: primeras interconexiones. III. NOTAS SOBRE LA RENOVACIÓN DE LA GOBERNANZA ECONÓMICA EUROPEA. IV. LA ABSORCIÓN DE LA COORDINACIÓN DE LAS POLÍTICAS SOCIALES Y DE EMPLEO EN LA NUEVA GOBERNANZA ECONÓMICA: 1. Fusión de los procedimientos. 2. La extensión de la coordinación económica a ciertos ámbitos materiales de la política social y de empleo: A. El impulso expansivo de las Directrices integradas y el desmantelamiento del MAC social; B. El activismo de los Reglamentos de coordinación económica en materia laboral y de protección social. 3. Debilitamiento de los presupuestos metodológicos de la coordinación social y de empleo: A. El nuevo carácter de las recomendaciones específicas por país en materia social y de empleo; B. El renovado papel de los fondos estructurales en el Semestre Europeo C. Una coordinación menos participativa e integradora. VI. REFLEXIONES CONCLUSIVAS.

\section{INTRODUCCIÓN}

Las crisis económicas y financieras que en los últimos años han afectado en mayor o menor medida a los Estados miembros de la Unión Europea han puesto de manifiesto el fracaso de las estrategias de coordinación de las políticas económicas. Ante esta circunstancia, la Unión Europea ha reaccionado articulando una profunda reforma del sistema de gobernanza económica.

A nivel procedimental, la reforma comporta la instauración de un paradigma omnicomprensivo, denominado Semestre Europeo, en el que converge el ejercicio de las competencias de coordinación que posee la Unión Europea no solo respecto de las políticas económicas, sino también respecto de las políticas sociales y de empleo. La puesta en marcha de esta nueva y poderosa maquinaria destinada a consolidar la Unión Económica y Monetaria abre un escenario caracterizado por las interconexiones y solapamientos entre los procesos de coordinación, pero sobre todo por la vis expansiva de la coordinación económica, que acaba por apoderarse de materias propias de las políticas sociales y de empleo, poniendo en cuestión el reparto de competencias diseñado en los Tratados. 
El presente artículo se propone analizar cómo se desenvuelven las competencias de coordinación de las políticas sociales y de empleo en el Semestre Europeo, para determinar hasta qué punto han sido absorbidas por los mecanismos de coordinación de las políticas económicas, y en qué medida ello comporta una pérdida de su identidad. Además, el examen de las nuevas interrelaciones entre las competencias de coordinación conduce hacia una reflexión acerca del papel de las políticas sociales y de empleo, así como de sus fuentes, en la Unión Económica reforzada hacia la que parece encaminarse de forma inexorable el proceso de integración.

\section{LA COORDINACIÓN DE LAS POLÍTICAS ECONÓMICAS, SOCIALES Y DE EMPLEO ANTES DE LA CRISIS}

\section{ALGUNAS SIMILITUDES Y VARIAS DIFERENCIAS ENTRE LAS COMPETENCIAS DE COORDINACIÓN}

Con la intención de dotar de mayor claridad el reparto de competencias entre los Estados miembros y la Unión Europea, el Tratado de Lisboa reunió en el art. 5 TFUE las competencias de coordinación de las políticas económicas, sociales y de empleo. Lejos de resultar intrascendente, su ubicación sistemática en un único precepto, al margen de las competencias compartidas y de las de soporte de la acción de los Estados, es indicativa del carácter sui generis de estas tres competencias, así como de ciertas interdependencias que adquieren inusitada relevancia en el contexto del mercado único y la Unión Económica y Monetaria ${ }^{2}$.

El principal rasgo distintivo de las competencias de coordinación frente a las demás es que no comportan una atribución, ni total ni parcial, del ejercicio de competencias soberanas a favor de la Unión Europea, sino tan solo el compromiso de los Estados de someterse a los procesos de coordinación que se pongan en marcha. Por consiguiente, no hay una acción material europea que reemplace a la acción estatal en virtud del principio de preferencia, como sucede en las competencias compartidas.

Ahora bien, más allá de este elemento que dota de cierta identidad común a las tres competencias, existen múltiples diferencias entre ellas. Así, atendien-

2 Roland BIEBER, "The Allocation of Economic Policy Competences in the European Union», en Loïc AZOULAI (ed.), The Question of Competence in the European Union, Oxford University Press, 2014, p. 90 y Lucia Serena ROSSI, "Does the Lisbon Treaty Provide a Clearer Separation of Competences between EU and Member States?», en Andrea BIONDI; Piet EECKHOUT y Stefanie RIPLEY (eds.), EU After Lisbon, Oxford University Press, 2012, p. 101. 
do a la función que desempeñan en el proceso de integración, resulta que tanto la competencia de coordinación de las políticas económicas, reconfigurada por el Tratado de Maastricht conforme a las exigencias del mercado único ${ }^{3}$, como la competencia de coordinación de las políticas de empleo, incorporada mediante el Tratado de Ámsterdam, se vinculan a la implantación de la Unión Económica y Monetaria. En efecto, en ambos casos, la elección de este tipo de competencias, aparentemente menos intrusivas que las compartidas, respondió a la necesidad de poner en marcha mecanismos de integración económica capaces de superar las reticencias de los Estados a ceder el ejercicio de sus competencias soberanas en asuntos tan delicados como la economía y el empleo ${ }^{4}$.

El nacimiento de la competencia de coordinación de las políticas sociales también guarda relación con el proyecto de implantación de la Unión Económica y Monetaria, aunque no de forma tan evidente. El título de Política Social, incorporado al Derecho originario mediante el Tratado de Ámsterdam, es en buena parte el resultado de las corrientes que abogaban por una política social con una función de contrapeso frente a los efectos negativos de la integración económica. Pero también puede percibirse en él un nuevo y aún tímido impulso hacia la coordinación trasnacional de las políticas sociales, alentado por la perspectiva de crecientes interconexiones económicas y presupuestarias entre los Estados miembros. Esta bipolaridad del título de Política Social se manifiesta en la incorporación de dos técnicas reguladoras con una orientación bien diversa. Por un lado, cediendo a las presiones en favor de una dimensión social del proceso de integración, se contempla una competencia compartida que permite la elaboración de directivas de mínimos en las materias enumeradas en el art. 153.1. a) a i) TFUE, si bien subordinada a la regla de la unanimidad. Y, por otro lado, abriendo sigilosamente la puerta a la influencia del mercado único sobre la política social, se incluye la posibilidad de que el Parlamento Europeo y el Consejo adopten medidas destinadas a fomentar la cooperación entre los Estados miembros en todas las materias sobre las que se pueden elaborar directivas, así como en dos más (art. 153.2.a) TFUE). Por su parte, el Tratado de Lisboa profundizó en la competencia de coordinación, atribuyendo también a la Comisión el poder para poner en marcha acciones de coordinación en determinados ámbitos de la política social (art. 156 TFUE) 5 .

3 Francis SNYDER, «EMU - Integration and Differentiation: Metaphor for European Union», en Paul CRAIG y Gráinne DE BÚRCA (eds.), The Evolution of EU Law, 2. ${ }^{\text {a }}$ ed., Oxford University Press, 2011, pp. 694-700.

4 Paul CRAIG, The Lisbon Treaty. Law, Politics and Treaty Reform, Oxford University Press, 2010, pp. 179-181.

5 José María MIRANDA BOTO, «Las competencias de la Unión Europea en materia social: panorama y perspectivas de futuro", Revista del Ministerio de Trabajo e Inmigración, núm. 92, 2011, p. 96. 
Por consiguiente, mientras la coordinación de las políticas económicas y de empleo es la única vía de la que dispone la Unión Europea para intervenir en estas áreas, en el plano social cuenta con una competencia compartida de armonización y otra de coordinación. Quizás por ello los arts. 2.3 y 5.1 y 2 TFUE se refieren a las competencias de coordinación de las políticas económicas y de empleo en términos preceptivos, dando a entender que estas competencias se ejercitarán necesariamente, con el debido respeto al principio de subsidiariedad, y en cambio el art. 5.3 TFUE se limita a indicar que «la Unión podrá tomar iniciativas para garantizar la coordinación de las políticas sociales de los Estados miembros». En el fondo, todo ello refleja el carácter más robusto de los ciclos de coordinación económica y de empleo, que se llevarán a cabo de forma ineludible como parte del proceso de construcción de la Unión Económica y Monetaria, frente a la fragilidad de la coordinación de las políticas sociales, cuyo rodaje depende de la voluntad política de cada momento ${ }^{6}$.

Las diferencias entre las competencias de coordinación que se desprenden de la observación del art. 5 TFUE se incrementan cuando se examina la regulación de los procesos de coordinación en los Títulos VIII, IX y X TFUE.

El procedimiento que cuenta con una regulación más pormenorizada es el económico. Y no solo debido al detalle con que los arts. 121 y 126 TFUE exponen el proceso de vigilancia multilateral en torno a las orientaciones generales de las políticas económicas (OGPE), así como el relativo a la disciplina de déficit, sino también porque dichos preceptos atribuyen al Parlamento Europeo y al Consejo la potestad de elaborar normas reglamentarias para desarrollar ambos procedimientos, sin que en la coordinación de las políticas sociales y de empleo haya atribuciones legislativas semejantes. De hecho, como consecuencia de esa habilitación, en 1997 se suscribió el Pacto de Estabilidad y Crecimiento (PEC), plasmado inmediatamente en dos Reglamentos que han sido hasta hace poco la única fuente de Derecho derivado que regulaba la coordinación de las políticas económicas ${ }^{7}$.

$6 \quad$ Klaus LÖRCHER, «Social Competences», en Niklas BRUUN, Klaus LÖRCHER e Isabelle SCHÖMANN (eds.), The Lisbon Treaty and Social Europe, Hart Publishing, Oxford y Portland, 2012, pp. 176, 177.

7 Reglamento (CE) 1467/97 del Consejo, de 7 de julio de 1997, relativo a la aceleración y clarificación del procedimiento de déficit excesivo (DO L 209, de 2 de agosto de 1997, p. 6) y Reglamento (CE) 1466/97 del Consejo, de 7 de julio de 1997, relativo al reforzamiento de la supervisión de las situaciones presupuestarias y a la supervisión y coordinación de las políticas económicas (DO L 209, de 2 de agosto de 1997 , p. 1). 
Por su parte, el procedimiento de coordinación de las políticas de empleo, descrito en el art. 148 TFUE, se aproxima formalmente al de coordinación de las políticas económicas, pues sigue el modelo del sistema de vigilancia multilateral del art. 121 TFUE. Esta similitud no es casual, sino que obedece a la conexión de la coordinación de las políticas de empleo con la integración económica y monetaria, así como al deseo, nunca alcanzado por completo, de propiciar un acercamiento de las políticas macroeconómicas de los Estados miembros mediante la coordinación de sus políticas de empleo. Pero la proximidad formal también conduce hacia la proximidad de los contenidos, pues los arts. 146.1 y 148.2 TFUE insisten en la necesidad de asegurar la coherencia entre los resultados alcanzados en los dos procesos, exigiendo la compatibilidad de la coordinación de las políticas de empleo con las OGPE. De este modo, además, se deja claro el carácter predominante de la coordinación económica sobre la de empleo.

Pese a todo, hay contrastes relevantes entre los dos procesos. Por ejemplo, aunque en ambos supuestos el Consejo y la Comisión lideran la coordinación, en el marco de las políticas de empleo se involucran en mayor medida el Parlamento Europeo y los Comités de Empleo, Económico y Social, y de las Regiones. Además, mientras el procedimiento de vigilancia multilateral prevé que la Comisión dirija advertencias a los Estados que no ajusten su política económica a las OGPE, la coordinación de las políticas de empleo no incorpora ningún elemento coercitivo, de modo que el cumplimiento de las recomendaciones del Consejo solo queda respaldado por la presión ejercida por el resto de los Estados miembros y las instituciones participantes.

Por último, el procedimiento de coordinación de las políticas sociales es el menos regulado de los tres. En realidad, ni el art. 153.2.a) ni el 156 TFUE describen un procedimiento de coordinación específico, aunque atribuyen bien al Parlamento Europeo y al Consejo, bien a la Comisión, la posibilidad de establecer orientaciones e indicadores, organizar el intercambio de mejores prácticas y preparar los elementos necesarios para el control y la evaluación periódicos. Tampoco se prevé la posibilidad de que el Consejo emita recomendaciones, ni se mencionan elementos coercitivos. Todo ello, unido al carácter más reciente de esta coordinación, que comenzó a desarrollarse a partir del año 2000 bajo la Estrategia de Lisboa, ha contribuido a que sea el proceso menos desarrollado y menos sólido de los tres a los que se refiere el art. 5 TFUE.

\section{LA PUESTA EN PRÁCTICA DE LAS COMPETENCIAS DE COORDINACIÓN: PRIMERAS INTERCONEXIONES}

Hasta 2010 la ejecución de las tres competencias de coordinación del art. 5 TFUE se llevó a cabo de forma independiente, en sintonía con la iden- 
tidad propia de cada una de ellas. Ello no quiere decir, sin embargo, que no haya habido interconexiones, en especial entre los procesos de coordinación de las políticas económicas y de empleo, que experimentaron un progresivo acercamiento ${ }^{8}$.

Desde la firma del Tratado de Ámsterdam hasta 2005 discurrió un periodo de intenso desarrollo de las competencias de coordinación. La Estrategia de Lisboa impulsó de forma decisiva la coordinación de las políticas de empleo y de las políticas sociales mediante el lanzamiento del método abierto de coordinación9 (MAC), que parecía ofrecer la clave para avanzar en el proceso de integración mediante soluciones pragmáticas que reducían la intensidad política de los asuntos. Las esperanzas que despertó el MAC como técnica de ejecución de las competencias de coordinación determinaron su extensión a la política social, donde pronto comenzaron a desarrollarse diversos procesos de coordinación sobre pensiones, asistencia sanitaria y cuidados de larga duración, e integración e inclusión social.

En 2005, tras percibirse los primeros signos de desaceleración del crecimiento y constatarse las dificultades para alcanzar los objetivos fijados cinco años atrás, se tomó la decisión de avecinar los procesos de coordinación de las políticas económicas y de empleo ${ }^{10}$. La imposibilidad de devaluar la moneda nacional para reactivar la competitividad desplaza el foco de atención hacia las reformas del mercado laboral, lo que explica el deseo de conectar de manera más estrecha ambos procesos de coordinación.

Por consiguiente, a partir de la revisión de la Estrategia de Lisboa, algunas fases de la coordinación económica y de empleo comenzaron a llevarse a cabo conjuntamente. También se redujo el número de directrices de empleo, priorizándose las relacionadas con el crecimiento económico y tendiendo a desaparecer las más próximas a criterios de justicia social ${ }^{11}$. De forma si-

8 Jean-Claude BARBIER, «Changes in Political Discourse from the Lisbon Strategy to Europe 2020: Tracing the Fate of 'Social Policy'", Working Paper ETUI, núm. 1, 2011, pp. 13-20.

9 Un examen exhaustivo de esta herramienta se encuentra en Stéphane DE LA ROSA, La méthode ouverte de coordination dans le système juridique communautaire, Bruylant, Bruxelles, 2007, pp. 15-187.

10 El plan para relanzar la Estrategia de Lisboa se condensa en la Comunicación al Consejo Europeo de primavera, «Trabajando juntos por el crecimiento y el empleo. Relanzamiento de la estrategia de Lisboa - Comunicación del Presidente Barroso de común acuerdo con el Vicepresidente Verheugen», COM(2005) 24 final, 2.2.2005.

11 Samantha VELLUTI, New Governance and the European Employment Strategy, Routledge, London and New York, 2010, pp. 122-180. 
multánea, los procesos de coordinación que habían comenzado a desarrollarse en el ámbito social se refundieron en un único MAC social ${ }^{12}$.

El último punto de inflexión antes de la reforma de la gobernanza económica vino dado por el lanzamiento en 2010 de una nueva estrategia política para la Unión Europea que se construye sobre la base de la Estrategia de Lisboa, intentando aprovechar su impulso y corregir sus puntos flacos.

La Estrategia Europa $2020^{13}$ centra su atención en el crecimiento económico, la estabilidad financiera y la salida de la crisis, lo cual provoca un cambio de talante respecto de las políticas sociales y de empleo ${ }^{14}$. Aunque en la década anterior ya se había percibido una creciente aproximación de la coordinación de las políticas sociales y de empleo a la órbita económica, los objetivos formulados en el Consejo Europeo de Lisboa y las directrices de empleo de los primeros años seguían vinculados a los tópicos clásicos del Derecho social europeo ${ }^{15}$. Es decir, a aquellos tópicos relacionados con la garantía de un conjunto de derechos de los trabajadores que habían orientado las escasas incursiones del método comunitario en el plano social, como igualdad y no discriminación por razón de sexo, conciliación de la vida laboral y familiar, y calidad del empleo, entre otros ${ }^{16}$. Por ello, la Estrategia Europea de Empleo complementaba y reforzaba las actuaciones llevadas a cabo a través de la legislación social existente y los fondos estructurales, conformando un sistema

12 Comunicación de la Comisión al Consejo, al Parlamento Europeo y al Comité Económico y Social Europeo y al Comité de las Regiones, «Trabajar juntos, trabajar mejor: un nuevo marco para la coordinación abierta de las políticas de protección social y de inclusión en la Unión Europea», $\operatorname{COM(2005)~} 706$ final, 22.12.2005 y Comunicación de la Comisión al Parlamento Europeo, al Consejo, al Comité Económico y Social Europeo y al Comité de las Regiones, «Un compromiso renovado en favor de la Europa social: reforzar el MAC en el ámbito de la protección social y la inclusión social», $\operatorname{COM}(2008) 418$ final, 2.7.2008. Comunicación de la Comisión, «Europa 2020: Una estrategia para un crecimiento inteligente, sostenible e integrador», $\operatorname{COM(2010)} 2020$ final, 3.3.2010. Richard HYMAN, «Trade Unions, Lisbon and Europe 2020: From Dream to Nightmare», LEQS Paper, núm. 45, 2011, pp. 3-21.

15 Caroline DE LA PORTE y Elke HEINS, «Game Change in EU and social policy: towards more European Integration», en Maria João RODRIGUES y Eleni XIARCHOGIANNOPOULOU (eds.), The Eurozone Crisis and the Transformation of EU Governance: Internal and External Implications, Ashgate, Farnham, 2014, pp. 166-171; Catherine BARNARD, EU Employment Law, Oxford University Press, 2012, pp. 115, 116.

16 Véase la Comunicación de la Comisión al Consejo, al Parlamento Europeo, al Comité Económico y Social y al Comité de las Regiones, "Agenda de política social», $\operatorname{COM}(2000) 379$ final, 28.6.2000. 
articulado en el que mediante diversas herramientas se perseguían los mismos fines ${ }^{17}$.

En cambio, la Estrategia Europa 2020 adopta una perspectiva más pragmática, orientada hacia el crecimiento del empleo en torno al concepto de flexiseguridad avanzado por la Comisión unos años antes, justo tras el relanzamiento de la Estrategia de Lisboa ${ }^{18}$. Los tópicos sociales clásicos quedan relegados, y adquieren nuevo protagonismo otros como formación, capacitación, flexibilidad laboral, lucha contra la exclusión social y la pobreza, o protección de los grupos vulnerables, mediante los que se trata de fortalecer la posición de las personas en el mercado laboral ${ }^{19}$. La tradicional orientación de la política social hacia la protección social deja paso a un enfoque centrado en la promoción y la inversión social, mucho más acorde con el impulso económico del Semestre Europeo ${ }^{20}$.

Esta reorientación de las políticas sociales y de empleo contribuye, desde un punto de vista material, a la pérdida de identidad de la coordinación social y de empleo y a su absorción dentro de las estructuras propias de la coordinación económica.

\section{NOTAS SOBRE LA RENOVACIÓN DE LA GOBERNANZA ECONÓMICA EUROPEA}

Uno de los factores desencadenantes de las crisis económico-financieras que azotan Europa desde 2007 reside en el desequilibrio entre una Unión Monetaria efectiva y una Unión Económica prácticamente inexistente. Desde

17 Claire KILPATRICK, «New EU Employment Governance and Constitutionalism», en Gráinne DE BÚRCA y Joanne SCOTT (eds.), Law and New Governance in the EU and the US, Hart Publishing, Oxford, 2006, pp. 131-134.

18 Libro Verde de la Comisión, «Modernizar el Derecho laboral para afrontar los retos del siglo XXI», COM (2006) 708, 22.11.2006.

19 Precisamente desde varios ámbitos se ha solicitado una mayor conexión de la Estrategia Europa 2020 con principios esenciales del Derecho social de la Unión Europea, como el de igualdad de género. Véase al respecto Employment Comittee and Social Protection Committee, "Joint EMCO-SPC opinion on the mid-term review of the Europe 2020 Strategy», 13809/14, 3.10.2014, apdo. 11. Véase también Francesco COSTAMAGNA, «The European Semester in Action: Strengthening Economic Policy Coordination while Weakening the Social Dimension?», Working Paper-LPF, núm. 5, 2013, p. 21.

20 Mary DALY, «Paradigms in EU Social Policy: A Critical Account of Europe 2020», Transfer: European Review of Labour and Research, vol. 18, núm. 3, 2012, pp. 282, 283. 
una perspectiva jurídica esta situación se explica por la asimetría entre una competencia exclusiva en materia monetaria, y una simple competencia de coordinación de las políticas económicas que apenas ha logrado garantizar la convergencia nominal sobre ciertos aspectos esenciales. Este desajuste ha sido y será una fuente de problemas prácticos de difícil solución mientras no se transfieran más competencias a la Unión Europea que le permitan intervenir de forma directa en ámbitos de la economía que hoy quedan fuera de su alcance $^{21}$.

Pero dada la necesidad de combatir de forma inmediata las crisis de los Estados miembros, y sin margen para debatir soluciones a largo plazo, la Unión Europea ha optado por hacer un uso intensivo - y extensivode la competencia ya existente de coordinación económica. Con este fin se ha pertrechado de los instrumentos necesarios para intervenir en todas aquellas materias que resulten relevantes para evitar desequilibrios externos o internos y atajar desde sus orígenes situaciones arriesgadas desde el punto de vista de la sostenibilidad financiera, aunque ello exija no prestar demasiada atención al reparto de competencias dispuesto en los Tra$\operatorname{tados}^{22}$. Obviamente, ello ha requerido la remodelación de las normas que desarrollaban los procesos de coordinación económica de los arts. $121 \mathrm{y}$ 126 TFUE.

Aunque no es posible analizar ahora la reforma del sistema de gobernanza económica ${ }^{23}$, sí es preciso destacar algunos aspectos que han contribuido a modificar el modo de ejecución de las competencias de coordinación y las interrelaciones entre ellas.

El efecto más evidente de la reforma ha sido un incremento notable del acervo normativo que regula el ejercicio de la competencia de coordinación

21 Manuel LÓPEZ ESCUDERO, «La nueva gobernanza económica de la Unión Europea: ¿una auténtica unión económica en formación?», RDCE, núm. 50, 2015, pp. 416-428.

22 Fritz W. SCHARPF, «After the Crash: A Perspective on Multilevel European Democracy», ELJ, vol. 21, núm. 3, 2015, p. 390.

23 Para un análisis exhaustivo de esta cuestión, véase Francisco ALDECOA LUZÁRRAGA, Carlos R. FERNÁNDEZ LIESA y Montserrat ABAD CASTELOS (dirs.), Gobernanza y reforma internacional tras la crisis financiera y económica: el papel de la Unión Europea, Marcial Pons, Madrid, 2014; Diego J. LIÑÁN NOGUERAS (dir.), Las crisis políticas y económicas: nuevos escenarios internacionales, Tecnos, Madrid, 2014; Andreu OLESTI RAYO (coord.), Crisis y coordinación de politicas económicas en la Unión Europea, Marcial Pons, Madrid, 2013 y Manuel LÓPEZ ESCUDERO, «La Unión Europea ante la crisis económica y financiera», $R D C E$, núm. 39, 2011, pp. 353-366 y «Las interminables reformas de la gobernanza económica de la zona euro», Revista General de Derecho Europeo, núm. 27, 2012, pp. 1-9. 
económica, compuesto hasta entonces por los dos reglamentos vinculados al PEC. En 2011 se acometió la primera oleada reformadora a través del denominado six pack, mediante el que se promulgaron cinco reglamentos y una directiva ${ }^{24}$, y en 2013 se completó la actuación legislativa a través de dos nuevos reglamentos, conocidos como two pack, cuyo ámbito de aplicación se circunscribe a los Estados de la Eurozona ${ }^{25}$. Las obligaciones que incorpora este nuevo bloque normativo se han reforzado mediante la suscripción de instrumentos intergubernamentales, entre los que destaca el Tratado de Estabilidad, Coordinación y Gobernanza en la Unión Económica y Monetaria ${ }^{26}$, que además impulsa la reforma de los ordenamientos internos para acoger las reglas de estabilidad presupuestaria ${ }^{27}$.

$24 \quad$ Reglamento (UE) 1173/2011 del Parlamento Europeo y del Consejo, de 16 de noviembre de 2011, sobre la ejecución efectiva de la supervisión presupuestaria en la zona del euro (DO L 306, de 23 de noviembre de 2011, p. 1); Reglamento (UE) 1174/2011 del Parlamento Europeo y del Consejo, de 16 de noviembre de 2011, relativo a las medidas de ejecución destinadas a corregir los desequilibrios macroeconómicos excesivos en la zona del euro (DO L 306, de 23 de noviembre de 2011, p. 8); Reglamento (UE) 1175/2011 del Parlamento Europeo y del Consejo, de 16 de noviembre de 2011, por el que se modifica el Reglamento (CE) 1466/97 del Consejo, relativo al refuerzo de la supervisión de las situaciones presupuestarias y a la supervisión y coordinación de las políticas económicas (DO L 306, de 23 de noviembre de 2011, p. 12); Reglamento (UE) 1176/2011 del Parlamento Europeo y del Consejo, de 16 de noviembre de 2011, relativo a la prevención y corrección de los desequilibrios macroeconómicos (DO L 306, de 23 de noviembre de 2011, p. 25); Reglamento (UE) 1177/2011 del Consejo, de 8 de noviembre de 2011, por el que se modifica el Reglamento (CE) 1467/97, relativo a la aceleración y clarificación del procedimiento de déficit excesivo (DO L 306, de 23 de noviembre de 2011, p. 33); y Directiva 2011/85/UE del Consejo, de 8 de noviembre de 2011, sobre los requisitos aplicables a los marcos presupuestarios de los Estados miembros (DO L 306, de 23 de noviembre de 2011, p. 41).

Reglamento (UE) 472/2013 del Parlamento Europeo y del Consejo, de 21 de mayo de 2013, sobre el reforzamiento de la supervisión económica y presupuestaria de los Estados miembros de la zona del euro cuya estabilidad financiera experimenta o corre el riesgo de experimentar graves dificultades (DO L 140, de 27 de mayo de 2013, p. 1) y Reglamento (UE) 473/2013 del Parlamento Europeo y del Consejo, de 21 de mayo de 2013, sobre disposiciones comunes para el seguimiento y la evaluación de los proyectos de planes presupuestarios y para la corrección del déficit excesivo de los Estados miembros de la zona del euro (DO L 140, de 27 de mayo de 2013, p. 11). BOE núm. 178, de 26 de julio de 2012, pp. 53541-53553.

27 José MARTÍN Y PÉREZ DE NANCLARES, «El nuevo Tratado de Estabilidad, Coordinación y Gobernanza de la UEM: reflexiones a propósito de una peculiar 
Tanto el six pack como el two pack han causado un fuerte impacto en la coordinación de las políticas sociales y de empleo. Sin embargo, al ser disposiciones vinculadas al Título VIII del TFUE, los agentes sociales europeos no fueron consultados durante su proceso de elaboración, como es preceptivo en las propuestas legislativas sobre política social (arts. 154.2 y 3 TFUE). Y aunque el Parlamento Europeo sí pudo intervenir en la elaboración de algunas de ellas como colegislador junto con el Consejo, su actuación no estuvo marcada por la reivindicación de mayores garantías de respeto del reparto constitucional de competencias, o de mayores cuotas de participación democrática en el nuevo sistema de gobernanza económica, como habría cabido esperar ${ }^{28}$.

Este incremento del acervo normativo ha conducido a un aumento de los instrumentos ordinarios de coordinación de las políticas económicas. Además de la reforma en profundidad de los componentes preventivo y corrector del PEC, se han añadido nuevos mecanismos a los ya existentes. Los más sobresalientes son el mecanismo de prevención y corrección de los desequilibrios macroeconómicos, que con base en el art. 121 TFUE somete a control la entera política económica de los Estados miembros ${ }^{29}$, y el calendario presupuestario común para los Estados de la eurozona, que permite verificar de forma temprana la coherencia de los presupuestos nacionales con los resultados de la gobernanza económica relativos a cada Estado.

Por fin, otro elemento distintivo de la reforma es el incremento de la coercitividad de la coordinación. De hecho, dos de los cinco reglamentos del six pack tienen por objeto exclusivo establecer y regular sanciones. Aparte de la reformulación de las sanciones asociadas al procedimiento de corrección de déficits excesivos, se prevén por primera vez sanciones en el brazo preventivo del PEC y en la fase correctora de los desequilibrios macroeconómicos excesivos, y se incorporan sanciones por manipulación de estadísticas. Todo ello sitúa a las recomendaciones del Consejo dictadas en el contexto de esos procedimientos en un terreno ambiguo entre las normas jurídicas y los actos

reforma realizada fuera de los Tratados constitutivos», $R D C E$, núm. 42, 2012, pp. 397-431.

Fritz W. SCHARPF, «Political Legitimacy in a Non-optimal Currency Area», MPIfG Discussion Paper, núm. 15, 2013, p. 24 y Cristina FASONE, «European Economic Governance and Parliamentary Representation. What Place for the European Parliament?», ELJ, vol. 20, núm. 2, 2014, pp.164-185.

F. Jesús CARRERA HERNÁNDEZ, «Nuevos instrumentos para la gobernanza económica en la Unión Europea: el procedimiento de prevención y corrección de los desequilibrios macroeconómicos - PDM», RDCE, núm. 44, 2013, pp. 63100. 
ejecutivos de naturaleza política ${ }^{30}$ y aleja la coordinación económica de los parámetros comúnmente atribuidos al soft law ${ }^{31}$.

Además, el legislador europeo manifiesta su deseo de que la imposición de sanciones a los Estados incumplidores sea «la regla y no la excepción» ${ }^{32}$, en clara referencia a episodios pasados en los que el Consejo bloqueó el curso de procedimientos de déficit excesivo por razones políticas ${ }^{33}$. Para evitar situaciones semejantes, la decisión de imponer multas reposa ahora sobre un sistema de mayoría cualificada inversa que incrementa el poder de la Comisión frente al Consejo y que ha sido objeto de duras críticas entre la doctrina ${ }^{34}$.

Pese a todo, los últimos acontecimientos muestran que sigue sin existir en este contexto una automaticidad entre incumplimiento de la obligación e imposición de la sanción ${ }^{35}$. Dada la naturaleza política de los procesos de gobernanza económica, la amplia discrecionalidad de los mecanismos de coordinación, y el hecho de que los Estados conserven su soberanía en materia económica, el correcto funcionamiento de los mecanismos coercitivos sigue

30 Kenneth ARMSTRONG, «The New Governance of EU Fiscal Discipline», ELRev, núm. 5, 2013, p. 615.

31 Fabien TERPAN, «Soft Law in the European Union - The Changing Nature of EU Law», ELJ, vol. 21, núm. 1, 2015, pp.77-84, 91, 92. Apdo. 16 del Preámbulo del Reglamento (UE) núm. 1174/2011.

33 Véase, al respecto, Manuel LÓPEZ ESCUDERO, «La reforma del Pacto de Estabilidad y Crecimiento», REDE, núm. 16, 2005, pp. 455-496.

34 Por todos, véase Rainer PALMSTORFER, "The Reverse Majority Voting under the 'Six Pack': A Bad Turn for the Union?», ELJ, núm. 20, 2014, pp. 186-203 y Carlos CLOSA MONTERO, «Los cambios institucionales en la gobernanza macroeconómica y fiscal de la UE: hacia una mutación constitucional europea», Revista de Estudios Políticos, núm. 165, 2014, pp. 83-88.

35 En 2015 se concedió una nueva prórroga a Francia para corregir su déficit excesivo antes de 2017 (Council Recommendation with a view to bringing and end to the excessive government deficit in France, ECOFIN 177, UEM 81, 5.3.2015). Desde 2013 España también se encuentra en una situación de prórroga condicionada a la adopción de reformas estructurales (Council Recommendation with a view to bringing an end to the situation of an excessive government deficit in Spain, ECOFIN 478, UEM 173, OC 361, 20.06.2013). Por otra parte, en 2015 se apreciaron desequilibrios macroeconómicos excesivos en Croacia, Bulgaria, Francia, Italia y Portugal, pero se decidió someter a estos Estados a un proceso de especial vigilancia, excluyendo la aplicación de las sanciones previstas en el Derecho derivado (Communication from the Commission to the European Parliament, the Council, the European Central Bank and the Eurogroup, «2015 European Semester: Assessment of growth challenges, prevention and correction of macroeconomic imbalances, and results of in-depth reviews under Regulation (EU) 1176/2011", $\operatorname{COM}(2015) 85$ final, 26.2.2015, apdo. 2, p. 4). 
dependiendo en última instancia de una valoración sobre la oportunidad política de la decisión ${ }^{36}$.

\section{LA ABSORCIÓN DE LA COORDINACIÓN DE LAS POLÍTICAS SOCIALES Y DE EMPLEO EN LA NUEVA GOBERNANZA ECONÓMICA}

La reforma bosquejada en el epígrafe anterior ha atraído la coordinación de las políticas sociales y de empleo a la órbita de la gobernanza económica, produciendo notables mutaciones en su carácter. La razón que ha conducido a esta situación es la relevancia del empleo y de ciertos aspectos de la política social para el buen funcionamiento de la Unión Económica y Monetaria, advertida con mayor intensidad durante la crisis, así como las dudas que siempre se han planteado en torno a la eficacia real del MAC social y de empleo para impulsar reformas a nivel nacional ${ }^{37}$.

Dicha atracción ha afectado a las competencias de coordinación social y de empleo tanto a nivel procedimental como material y metodológico, como se verá a continuación.

\section{FUSIÓN DE LOS PROCEDIMIENTOS}

Uno de los propósitos que persigue la nueva gobernanza económica es incrementar la conexión de los procesos de coordinación para garantizar su coherencia y refuerzo mutuo. Esta necesidad es ahora mayor, no solo porque hay más mecanismos de coordinación, sino porque los que ya existían se tornan más complejos. Sin embargo, tras el estrechamiento de los canales de coordinación late también el propósito no declarado de extender la gobernanza económica a otros ámbitos materiales limítrofes con el área de las competencias económicas.

36 Dermot HODSON e Imelda MAHER, «Soft law and sanctions: economic policy co-ordination and reform of the Stability and Growth Pact», Journal of European Public Policy, vol. 11, núm. 5, 2004, pp. 807, 808; Jonathan ZEITLIN y Bart VANHERCKE, Socializing the European Semester? Economic Governance and Social Policy Coordination in Europe 2020, Swedish Institute for European Policy Studies (SIEPS), Report núm. 7, 2014, pp. 56, 57.

37 Como muestra de ese debate, a favor de su efectividad, véase Martin HEIDENREICH y Jonathan ZEITLIN (eds.), Changing European Employment and Welfare Regimes. The Influence of the Open Method of Coordination on National Reforms, Routledge, London and New York, 2009. 
La integración de los mecanismos de coordinación se lleva a cabo vinculando sus fases a un calendario común cuyo resultado es la puesta en marcha de un macroproceso de coordinación denominado Semestre Europeo.

En el Semestre Europeo se dan cita, por un lado, los mecanismos de coordinación relacionados con la Estrategia Europa 2020, esto es, la vigilancia multilateral desarrollada en torno a las OGPE, la coordinación de las políticas de empleo y la supervisión orientada a la prevención de los desequilibrios macroeconómicos. Y, por otro lado, también forma parte del Semestre Europeo el componente preventivo del PEC, que supervisa si los Estados miembros han alcanzado o mantienen su objetivo presupuestario a medio plazo, mediante el análisis de los Programas de Estabilidad o de Convergencia ${ }^{38}$.

A estos cuatro procesos de coordinación hay que añadir el seguimiento de los compromisos asumidos por algunos Estados miembros en el Pacto por el Euro Plus ${ }^{39}$. Y además, hay que tener en cuenta que aunque los procedimientos de corrección del déficit excesivo y de los desequilibrios macroeconómicos excesivos no se desarrollan en el Semestre Europeo, la decisión de iniciarlos se toma a la vista de sus resultados.

Por consiguiente, la coordinación de las políticas de empleo se incrusta en el corazón de la compleja maquinaria a través de la cual la Unión Europea ejercita su competencia de coordinación de las políticas económicas, culminando así la aproximación iniciada en el relanzamiento de la Estrategia de Lisboa.

La Estrategia Europa 2020 propone una mayor interrelación entre los informes y evaluaciones del PEC y los de coordinación de las políticas económicas y de empleo. Ello se consigue, a nivel formal, sincronizando los procesos de elaboración y presentación de los Programas de Estabilidad o Convergencia y de los Planes Nacionales de Reformas. Incluso los resultados de ambos procesos se plasman ahora en un único documento que incorpora tanto el Dictamen del Consejo sobre los Programas de Estabilidad o Convergencia como las Recomendaciones específicas por país en torno a las Directrices integradas de las políticas económicas y de empleo. Esta aproximación temporal y documental de los procesos persigue una aproximación material, que se llevará a cabo incluyendo las "referencias cruzadas necesarias» que permitan «reunir los medios y objetivos» perseguidos por ambos procedimientos para garantizar su coherencia ${ }^{40}$.

\footnotetext{
38 Art. 2 bis.2 del Reglamento (CE) 1466/97.

39 Anexo I de las Conclusiones del Consejo Europeo celebrado el 24 y 25 de marzo de 2011, EUCO 10/1/11 Rev. 1, 20.4.2011.

40 Comunicación de la Comisión, «Europa 2020....», op. cit., nota 12, apdo. 5.1.
} 
Pero, yendo aún más lejos, se llega a evocar una completa absorción de la coordinación de las políticas de empleo en la coordinación económica, al señalar que las recomendaciones sobre empleo "podrían canalizarse, en la medida en que tienen implicaciones macroeconómicas, mediante recomendaciones con arreglo a las GOPE ${ }^{41}$. Es decir, cuando una materia atraiga el interés tanto de las políticas macroeconómicas como de las de empleo, la Estrategia Europa 2020 parece sugerir que la coordinación debería llevarse a cabo mediante los mecanismos vinculados al art. 121 TFUE, y no a través del procedimiento del art. 148 TFUE.

En cierto modo, la agrupación de los procedimientos de coordinación de las políticas económicas y de empleo en un único marco de coordinación es conforme con el enfoque conjunto de ambas competencias que reflejan los arts. 2.3 y 5.1 y 2 TFUE, y con el diseño del art. 148 TFUE siguiendo el modelo del art. 121 TFUE. Pero la situación es completamente distinta por lo que se refiere a la coordinación de la política social.

Quizás haciendo uso de la facultad potestativa con la que el art. 5.3 TFUE contempla la coordinación de las políticas sociales, el ejercicio de esta competencia no ha sido incluido en el Semestre Europeo. Esta exclusión podría apuntar a una mayor independencia de la coordinación de las políticas sociales respecto de los procesos de coordinación económica, lo que resultaría positivo si aquella contase con instrumentos suficientemente eficaces. Pero a continuación se verá que no ha sido así.

\section{LA EXTENSIÓN DE LA COORDINACIÓN ECONÓMICA A CIERTOS ÁMBITOS MATERIALES DE LA POLÍTICA SOCIAL Y DE EMPLEO}

\section{A. El impulso expansivo de las Directrices integradas y el desmantelamiento del MAC social}

El contenido social y de empleo de la Estrategia Europa 2020 se hace patente ya en una de sus tres prioridades, denominada "crecimiento integrador», que se refiere al «fomento de una economía con un alto nivel de empleo que redunde en la cohesión económica, social y territorial». En el marco de las políticas económicas y de empleo el instrumento de ejecución de la Estrategia son las Directrices integradas, que desde 2005 aglutinan tanto las OGPE como las orientaciones generales de las políticas de empleo.

Si se observan las directrices integradas desde la perspectiva del reparto de competencias del TFUE, enseguida se advierten ciertas distorsiones en el uso de las competencias de coordinación, pues las OGPE inciden en profun-

\footnotetext{
$41 \quad$ Ibid.
} 
didad en aspectos relativos al empleo y la política social y, a su vez, las directrices de las políticas de empleo abordan cuestiones claramente ubicadas en el ámbito de la política social. Esta situación no es completamente novedosa, ya que desde sus primeras formulaciones las OGPE se han referido a tópicos socio-laborales, si bien de manera parca, dada la necesidad de respetar la autonomía de los procesos paralelos de coordinación de las políticas sociales y de empleo. Lo que ahora llama la atención es la exhaustividad de las OGPE en algunas materias sociales y laborales relacionadas con los criterios de convergencia del art. 140 TFUE.

Así, por ejemplo, tanto las OGPE de 2010, vigentes hasta 2014, como las de 2015 se refieren a la necesidad de combatir los desequilibrios macroeconómicos abordando, entre otros aspectos, la regulación del mercado laboral o la evolución salarial ${ }^{42}$. La imprecisa referencia al mercado laboral ha permitido que las herramientas del Semestre Europeo incidan en cuestiones como la legislación protectora del empleo, la flexibilización de la jornada laboral, el fomento de la movilidad funcional, la prevención de la segmentación del mercado laboral o el incremento de la oferta de formas de trabajo flexible ${ }^{43}$. El punto de partida no declarado de esas intervenciones ha sido la consideración de dichas instituciones laborales como obstáculos para el incremento de la competitividad, por lo que las reformas aconsejadas han seguido una línea desreguladora. Todo ello ha propiciado profundos cambios en los sistemas laborales de los Estados miembros de la Unión Europea ${ }^{44}$.

42 Recomendación 2010/410/UE del Consejo, de 13 de julio de 2010, sobre directrices generales para las políticas económicas de los Estados miembros y de la Unión (DO L 191, de 23 de julio de 2010, p. 28) y Decisión 2010/707/UE del Consejo, de 21 de octubre de 2010, relativa a las orientaciones para las políticas de empleo de los Estados miembros (DO L 308, de 24 de noviembre de 2010, p. 46). Recomendación del Consejo relativa a las orientaciones generales para las políticas económicas de los Estados miembros y de la Unión, $\operatorname{COM}(2015) 99$ final, 2.3.2015 y Propuesta de Decisión del Consejo relativa a las orientaciones para las políticas de empleo de los Estados miembros, Bruselas, 19 de junio de 2015.

43 Stefan CLAUWAERT, "The Country-specific Recommendations (CSRs) in the Social Field. An Overview and Initial Comparison», ETUI - Background analysis, núm. 2, 2013, pp. 5-40; Stefan CLAUWAERT e Isabelle SCHÖMANN, "The Crisis and National Labour Law Reforms: A Mapping Exercise», ETUI Working Paper, núm. 4, 2012, pp. 5-17.

44 Marie-Cécile ESCANDE-VARNIOL, Sylvaine LAULOM y Emmanuelle MAZUYER (dirs.), Quel Droit social dans une Europe en crise?, Larcier, Paris, 2013, pp. 21-60 y 343388 y Francesco COSTAMAGNA, «The European Semester in Action: Strengthening 
Por lo que se refiere a la evolución salarial, desde 2010 las OGPE revelan la obsesión de la Unión Europea por que los sistemas de negociación salarial y la evolución de los costes laborales sean coherentes con la estabilidad de los precios y las tendencias de la productividad a medio plazo, sugiriendo para ello intervenciones sobre los salarios del sector público y sobre la negociación colectiva salarial.

Las pensiones también han sido objeto de atención en el marco del Semestre Europeo. La primera de las directrices integradas de las OGPE de 2010, relativa a la calidad y viabilidad de las finanzas públicas, sugería a los Estados miembros la reforma del gasto público relacionado con el envejecimiento, en especial del gasto en pensiones y salud, así como el incremento de la edad de jubilación efectiva, a fin de garantizar la sostenibilidad financiera de los sistemas de bienestar social. En la actualidad, las referencias a las pensiones desaparecen de las OGPE y se sitúan en la octava orientación para las políticas de empleo, pero se mantiene el enfoque centrado en su sostenibilidad y «adecuación». Quedan así desterrados los intentos por poner en marcha un MAC de las pensiones, haciendo uso de la competencia de coordinación de las políticas sociales, que habían tenido lugar durante la Estrategia de Lisboa ${ }^{45}$.

Por último, otra de las áreas de la política social absorbida por los mecanismos del Semestre Europeo ha sido la lucha contra la pobreza y la exclusión social, que conforma una de las iniciativas emblemáticas de la Estrategia Europa $2020^{46}$. Esta temática ha estado asociada a la política social desde que en 1975 la Comunidad Europea pusiera en marcha una serie de programas para combatir la pobreza y la exclusión social que tuvieron continuidad hasta 1994. Con la incorporación a los Tratados del Título de Política Social, la lucha contra la exclusión social se plasmó en el art. 153.1.j) TFUE, habilitando

Economic Policy Coordination while Weakening the Social Dimension?», Working Paper-LPF, núm. 5, 2013, pp. 18, 19.

45 Comunicación de la Comisión al Consejo, al Parlamento Europeo y al Comité Económico y Social, «Apoyo a las estrategias nacionales para garantizar pensiones seguras y viables mediante un planteamiento integrado", COM(2001) 362 final, 3.7.2001. Sobre el nacimiento, desarrollo y características del MAC en materia de pensiones, véase David NATALI y Caroline DE LA PORTE, «Participation through the Lisbon strategy: comparing the European Employment Strategy and pensions OMC», Transfer. European Review of Labour and Research, vol. 15, núm. 1, 2009, pp. 80-86.

46 Comunicación de la Comisión al Parlamento Europeo, al Consejo, al Comité Económico y Social Europeo y al Comité de las Regiones, «La Plataforma Europea contra la Pobreza y la Exclusión Social: Un marco europeo para la cohesión social y territorial», $\operatorname{COM}(2010) 758$ final, 16.12.2010, apdo. 1. 
al Parlamento Europeo y al Consejo para adoptar medidas de fomento de la cooperación de los Estados miembros. De acuerdo con ello, el MAC social desarrollado bajo la Estrategia de Lisboa incidió precisamente en la lucha contra la exclusión social ${ }^{47}$.

A pesar de ello, la Estrategia Europa 2020 no vincula esta iniciativa emblemática ni con la competencia de coordinación de las políticas sociales, ni con el MAC social de la etapa de Lisboa. Por el contrario, la promoción de la inclusión social y la lucha contra la pobreza se ha enunciado como una orientación de las políticas de empleo tanto en 2010 como en 2015. Esto significa que desde entonces las actuaciones llevadas a cabo en esta materia se sitúan en el renovado marco de la gobernanza económica ${ }^{48}$.

La elección de las competencias de coordinación de las políticas económicas y de empleo para abordar cuestiones de la esfera social, sustituyendo así la competencia de coordinación de las políticas sociales, tiene consecuencias muy relevantes.

En primer lugar, el carácter de las actuaciones cambia drásticamente, pues los objetivos rectores de las políticas sociales enunciados en el art. 151 TFUE son desplazados por los objetivos que presiden la actuación de la Unión Europea en el ámbito económico y del empleo (arts. 119 y 145 TFUE).

Bajo esta nueva lectura en clave económica y de empleo, la lucha contra la pobreza y la exclusión social se asocia con tópicos como empleabilidad, formación, lucha contra la discriminación en el empleo y sistemas de protección social modernizados; las pensiones se analizan desde el punto de vista de su sostenibilidad financiera y de la necesidad de evitar un gasto público excesivo; y la consideración del salario como un elemento macroeconómico deja en la sombra su faceta de compensación justa por el trabajo prestado y pone en entredicho la libertad de la negociación colectiva para proceder a su determinación.

En segundo lugar, al desplazarse al plano económico, la coordinación sobre la reforma del mercado laboral, salarios y protección social se llevará a cabo mediante el proceso de vigilancia multilateral del art. $121 \mathrm{TFUE}$, el mecanismo de prevención de desequilibrios macroeconómicos y el brazo preventivo del PEC. Todos estos procesos sustituyen a la cooperación descrita en

47 Kenneth ARMSTRONG, Governing Social Inclusion. Europeanization through Policy Coordination, Oxford University Press, 2010, pp. 16-26 y 64-95.

48 Sonia BEKKER y Saskia KLOSSE, «EU Governance of Economic and Social Policies: Chances and Challenges for Social Europe», Tilburg Law School Legal Studies Research Paper Series, núm. 1, 2014, p. 112. 
los arts. 153.2.a) y 156 TFUE, basada en el intercambio de experiencias en un contexto dialógico más próximo al modelo tradicional de soft law ${ }^{49}$.

En tercer lugar, y como consecuencia de lo anterior, las instituciones que asumen la coordinación sobre las materias apuntadas son las dominantes en el Semestre Europeo, es decir, Comisión - y en particular, la Dirección General de Asuntos Económicos y Financieros ${ }^{50}$ - y Consejo, auxiliadas por el Comité de Empleo. En cambio, si se hiciese uso de la competencia prevista en los arts. 153.2.a) y 156 TFUE, la cooperación sería estimulada por el Parlamento Europeo y el Consejo, o por la Comisión, respectivamente. Y tendría un carácter mucho más abierto y participativo, ya que habría que garantizar la presencia de los agentes sociales, según lo dispuesto en el art. 152 TFUE, y de otras instituciones, como el Comité Económico y Social o el Parlamento Europeo, expresamente citadas en el art. 156 TFUE.

Estas apreciaciones muestran que la integración en el Semestre Europeo de aspectos sociales mediante su absorción en las competencias de coordinación económica y de empleo, lejos de «socializar» el Semestre Europeo, produce una intervención marcadamente económica en estas materias y desplaza las actuaciones que puedan llevarse a cabo desde otras bases competenciales más adecuadas.

A este respecto, es muy significativo que de forma simultánea a la incorporación de algunas materias propias de la política social en las directrices integradas, la Comisión decidiese cancelar el resto de los mecanismos mediante los que se desarrollaba el MAC social, como el requerimiento a los Estados miembros para que presentasen Informes Nacionales Sociales, o la elaboración con carácter anual de un Informe Conjunto sobre Protección Social e Inclusión Social. Esta circunstancia ha sido interpretada como el deseo de que toda la labor de coordinación se canalice únicamente a través del Semestre Europeo para garantizar una mayor eficacia de las medidas propuestas ${ }^{51}$, aunque los datos no avalan esta hipótesis ${ }^{52}$.

49 Comunicación de la Comisión, «La Plataforma Europea contra la Pobreza...», op. cit., nota 45, apdo. 3.5. Ya en la fase final de la Estrategia de Lisboa la Comisión expresó el deseo de aplicar al MAC social el instrumental propio de la coordinación de las políticas económicas y sociales. Véase al respecto la Comunicación de la Comisión, «Un compromiso renovado...», op. cit., nota 11.

50 ZEITLIN y VANHERCKE, op. cit., nota 35, p. 34.

51 Kenneth ARMSTRONG, «EU Social Policy and the Governance Architecture of Europe 2020», Transfer: European Review of Labour and Research, vol. 18, núm. 3, 2012, p. 296 y ZEITLIN y VANHERCKE, op. cit., nota 35, pp. 29 y 30.

52 La propia Comisión ha reconocido que el número de personas al borde de la pobreza y la exclusión social en la UE pasó de 114 millones en 2009 a 124 millones en 2012, alejándose del objetivo fijado para 2020, que es reducir esa cifra a 96,4 millones de 
En contraste con el abandono del MAC social por parte de la Comisión, el Comité de Protección Social, al margen del Semestre Europeo y por propia iniciativa, desarrolla una actividad de análisis en profundidad de determinados temas relevantes desde el punto de vista social, intentando estimular la participación voluntaria de los Estados y el aprendizaje mutuo sobre las bases del antiguo MAC. Así, desde 2012 el Comité invita regularmente a los Estados a presentar Informes Nacionales Sociales y se ha comprometido a elaborar un Informe anual sobre la situación social en Europa ${ }^{53}$. De este modo, puede decirse que el MAC social pervive, pero sin el apoyo directo de las más altas instituciones europeas.

Esta situación pone de relieve las dificultades e incoherencias del nuevo marco de coordinación respecto de la política social. Una vez que se crea un macroaparato de coordinación, como el Semestre Europeo, dejar fuera de tal maquinaria la coordinación de las políticas sociales puede conducir a su marginación, debilitándola. Pero su integración en el marco global de gobernanza comporta el riesgo de que la coordinación de la política social pierda su carácter y sus elementos distintivos, siendo absorbida por las técnicas de coordinación dominantes.

El hecho de que el MAC social se esté desarrollando bajo el impulso del Comité de Protección Social despierta dudas y temores sobre su viabilidad. Por un lado, parece conveniente explorar las sinergias que pueden surgir entre este sistema de coordinación voluntario, basado en el aprendizaje mutuo, y el desarrollo de las materias de contenido social que aborda el Semestre Europeo $^{54}$. Pero, por otro lado, también parece necesario reforzar el MAC social con la intervención de la Comisión, o bien del Parlamento Europeo y del Consejo, para dar sustento político e institucional a las temáticas que constituyen su objeto de atención ${ }^{55}$. Y es que, pese a que el desarrollo del MAC social por el Comité de Protección Social merezca una valoración positiva, su efectividad como elemento de contraste frente a la tendencia economicista de las políticas sociales forjadas en el Semestre Europeo no es posible sin el apoyo de las instituciones europeas.

personas (Comunicación de la Comisión al Parlamento Europeo, al Consejo, al Comité Económico y Social Europeo y al Comité de las Regiones, «Balance de la Estrategia Europa 2020 para un crecimiento inteligente, sostenible e integrador», $\operatorname{COM}(2014) 130$ final, 5.3.2014, apdo. 1.3).

53 Social Protection Committee, "Opinion on Reinvigorating the Social OMC in the Context of the Europe 2020 Strategy», 10405/11, 23.5.2011.

54 En esta línea, ZEITLIN y VANHERCKE, op. cit., nota 35, pp. 21, 22.

55 En este sentido, véase la propuesta de ARMSTRONG, «EU Social Policy ..», op. cit., nota 50, p. 297. 


\section{B. El activismo de los Reglamentos de coordinación económica en materia laboral y de protección social}

La apropiación de contenidos típicamente sociolaborales por parte de la coordinación económica ha traspasado el plano de ejecución de las políticas para plasmarse en las normas que redefinen la extensión de la competencia de coordinación de las políticas económicas. Mientras los dos Reglamentos del PEC vigentes hasta 2011 no mencionaban en absoluto cuestiones sociolaborales, la reforma operada por el six pack y el two pack ha introducido en el acervo normativo de la gobernanza económica referencias expresas a la política salarial de los Estados miembros y a los sistemas de Seguridad Social ${ }^{56}$.

Esta iniciativa revela el deseo de blindar las actuales opciones de política económica mediante su inserción en las normas de derecho derivado que, dada su actual relevancia, conforman una especie de bloque de constitucionalidad económica ${ }^{57}$. La incorporación de disposiciones relativas a los salarios y las pensiones en los Reglamentos convierte su control y supervisión en un contenido necesario del Semestre Europeo, poniéndolo a salvo de posibles vaivenes en las estrategias políticas que presiden la coordinación de las políticas económicas.

A su vez, la inclusión de estas referencias en la legislación derivada impone significativas limitaciones sobre las políticas salariales y sociales de los Estados, alterando el reparto de competencias dispuesto en los Tratados en beneficio de un creciente poder de la Unión Europea.

El actual marco normativo de la gobernanza económica no solo permite la intervención sobre la política salarial nacional en circunstancias excepcionales, como la existencia de desequilibrios macroeconómicos excesivos, o bien, tratándose de Estados de la eurozona, la existencia de déficits excesivos o la necesidad de solicitar asistencia financiera ${ }^{58}$. Al margen de esas situaciones límite, se instaura un control ordinario y temprano de las políticas salariales de los Estados miembros a través del componente preventivo del mecanismo de desequilibrios macroeconómicos, que presta especial atención a los costes laborales unitarios ${ }^{59}$.

56 Nora M. MARTÍNEZ YÁÑEZ, «La intromisión de la gobernanza económica europea en la negociación colectiva salarial y los sistemas públicos de pensiones», Revista de Trabajo y Seguridad Social. CEF, núm. 389-390, 2015, pp. 10-38.

57 CLOSA MONTERO, op. cit., nota 33, pp. 66, 68.

58 Apdo. 7 del Preámbulo y art. 1.2 del Reglamento (UE) 473/2013, y art. 7 del Reglamento (UE) 472/2013, respectivamente.

59 European Commission, Scoreboard for the surveillance of macroeconomic imbalances, Occasional Papers, núm. 92, 2012, pp. 14-16. 
Así, si sobre la base del examen exhaustivo la Comisión concluye que un Estado está experimentando desequilibrios, el Consejo deberá dirigir a dicho Estado las recomendaciones que considere necesarias para poner fin a esa situación y prevenir así que los desequilibrios se tornen excesivos. El propio Reglamento reconoce que las recomendaciones pueden abarcar los principales ámbitos de la política económica, incluidas las políticas presupuestaria y salarial, o las condiciones de funcionamiento de los mercados laborales ${ }^{60}$.

También de forma ordinaria y preventiva, para garantizar la sostenibilidad de las finanzas públicas, la supervisión de los planes presupuestarios anuales de los Estados de la eurozona puede incidir en la determinación de los salarios de los empleados públicos ${ }^{61}$.

La otra materia propia del ámbito social que aparece de forma transversal en los Reglamentos de la gobernanza económica es el sistema de Seguridad Social, y en particular las pensiones. La incidencia del gasto en protección social sobre la sostenibilidad de las finanzas públicas determina su sometimiento a especial supervisión. A tales efectos, se obliga a que tanto los Programas de Estabilidad como los Programas de Convergencia incluyan información acerca de las obligaciones relacionadas con el envejecimiento y pasivos contingentes que puedan tener una gran incidencia en las cuentas de las Administraciones Públicas ${ }^{62}$.

Y, de nuevo, la supervisión a la que están sometidos los Estados de la eurozona es más estrecha, pues el proyecto de plan presupuestario que han de presentar en otoño a la Comisión y al Eurogrupo antes de que arranque formalmente el Semestre Europeo debe contener información pertinente sobre los gastos de las Administraciones Públicas por función, incluidos los sectores de educación, asistencia sanitaria y empleo ${ }^{63}$.

Pero lo más llamativo de la intervención de los Reglamentos sobre las pensiones es el decidido impulso de un concreto modelo de pensiones de vejez, que se califica como multipilar, y que se caracteriza por la inclusión de un pilar obligatorio de financiación pública, complementado por otros pilares de financiación privada, a cargo de las empresas, de los trabajadores, o de ambos. Las reformas de los sistemas de pensiones hacia el modelo multipilar se fomentan concediendo ventajas a los Estados que las adopten tanto en el componente preventivo como en el componente corrector del PEC. En el componente preventivo tales ventajas consisten en la admisión de desviaciones de la trayectoria de ajuste hacia el objetivo presupuestario a medio plazo o del objetivo mismo,

\footnotetext{
60 Art. 6 y apdos. 20 y 25 del Preámbulo del Reglamento (UE) 1176/2011.

61 Apdo. 7 del Preámbulo y art. 1.2 del Reglamento (UE) 473/2013.

62 Arts. 3.2.a bis) y 7.2.a bis) del Reglamento (CE) 1466/97.

63 Art. 6.3.d) Reglamento (UE) 473/2013.
} 
en una proporción que refleje el ahorro que comportará la reforma en el gasto público $^{64}$. Este margen de desviación puede evitar que se pongan en marcha los nuevos elementos coercitivos introducidos por la reforma en el componente preventivo del $\mathrm{PEC}^{65}$.

Por su parte, en el contexto del componente corrector, la puesta en marcha de dicho tipo de reformas será tenida en cuenta en la evaluación del cumplimiento de los criterios de déficit y deuda previa a la decisión de iniciar o no un procedimiento de déficit excesivo; pero también, en caso de que este ya se haya iniciado, en las fases del mismo, al evaluar la evolución de las cifras de déficit, al decidir si se revocan las advertencias, depósitos, multas y sanciones adoptadas, o al decidir poner fin al procedimiento de déficit excesivo ${ }^{66}$.

\section{DEBILITAMIENTO DE LOS PRESUPUESTOS METODOLÓGICOS DE LA COORDINACIÓN SOCIAL Y DE EMPLEO}

Uno de los aspectos más originales de la Estrategia de Lisboa fue el lanzamiento de una metodología específica para ejecutar las competencias de coordinación, que obtuvo particular arraigo en materia social y de empleo ${ }^{67}$. Las técnicas del MAC han sido objeto de un análisis doctrinal exhaustivo, y en ellas destaca la participación de múltiples agentes procedentes de diversos niveles políticos y sociales, la condivisión de los poderes decisorios, la adopción de decisiones mediante procesos deliberativos, el aprendizaje mutuo y

64 Arts. 5 y 9 del Reglamento (CE) 1466/97.

65 En concreto, una advertencia de la Comisión, y posteriormente una recomendación del Consejo (arts. 6.2 y 10.2 del Reglamento (CE) 1466/97). Pero si se trata de un Estado de la eurozona, el incumplimiento de la recomendación del Consejo puede desembocar en la obligación de constituir un depósito con intereses equivalente al 0,2\% del PIB correspondiente al ejercicio del año anterior (Art. 4 del Reglamento (UE) $1173 / 2011$.

66 Arts. 2.5 y 7 del Reglamento (CE) 1467/97. Recientemente la Comisión ha aclarado que el procedimiento de déficit excesivo puede terminarse incluso si el déficit sobrepasa el 3\% del PIB, a condición de que el exceso sea íntegramente imputable a los costes de aplicación de la reforma de pensiones, que el déficit haya disminuido de forma sustancial y continuada, y que se haya alcanzado un nivel próximo al valor de referencia (Apdo. 3.2 de la Comunicación de la Comisión, al Parlamento Europeo, al Consejo, al Banco Central Europeo, al Comité Económico y Social Europeo, al Comité de las Regiones y al Banco Europeo de Inversiones, «Aprovechar al máximo la flexibilidad que ofrecen las actuales disposiciones del Pacto de Estabilidad y Crecimiento», COM(2015) 12 final, 13.1.2015).

67 "Conclusiones de la Presidencia», Consejo Europeo de Lisboa de 23 y 24 de marzo de 2000, apdos. 37 a 40. 
la elección de las mejores prácticas, la flexibilidad de los procedimientos y las técnicas, y la concesión de un amplio margen a los Estados para determinar los modos de cumplir los objetivos más acordes con su situación particular y sus tradiciones ${ }^{68}$.

Pese a que las citadas características hacen del MAC una técnica de coordinación novedosa, es innegable su vinculación con los instrumentos de coordinación económica, y en particular con las OGPE. Sin embargo, el distinto carácter de las competencias de coordinación económica, frente a las competencias de coordinación social y de empleo, determinó la aplicación de métodos diferentes en uno y otro ámbito ${ }^{69}$.

Mientras la Estrategia Europea de Empleo se centró en mayor medida en la construcción del consenso sobre la orientación común de las políticas de empleo, sin ejercer demasiada presión sobre los medios para la consecución de los objetivos, la necesidad de obtener resultados mensurables en el ámbito económico determinó que la coordinación desarrollada en esta esfera impusiese criterios estrictos e imperativos no solo en cuanto a los fines sino también respecto de los medios para conseguirlos ${ }^{70}$.

La actual fusión de los procesos de coordinación económica y de empleo implica una reorientación del MAC hacia el modelo desarrollado en el ámbito económico. El MAC que actualmente tiene lugar en el Semestre Europeo ha perdido buena parte del carácter abierto que operaba como garantía de respeto de la soberanía y el pluralismo político de los Estados, a la vez que se ha erosionado su carácter participativo y deliberativo.

\section{A. El nuevo carácter de las recomendaciones específicas por país en materia social y de empleo}

En las recomendaciones específicas por país se condensan los resultados de los procesos de coordinación de las políticas económicas y de empleo, de la supervisión presupuestaria derivada del brazo preventivo del PEC y de los exámenes exhaustivos que puedan llevarse a cabo en el marco del procedimiento de desequilibrios macroeconómicos ${ }^{71}$. Aunque en alguna ocasión el preámbulo contiene referencias a las bases jurídicas de las recomendaciones, nunca se indica qué recomendaciones proceden de la coordinación de las po-

\footnotetext{
68 DE LA ROSA, loc. cit., nota 8.

69 Un análisis de las diferencias entre ambos puede verse en David M. TRUBEK, Patrick COTTRELL y Mark NANCE, «'Soft Law', 'Hard Law', and EU Integration», en DE BÚRCA y SCOTT (eds.), op. cit., nota 16, pp. 76-90.

70 DE LA ROSA, op. cit., nota 8, p. 87.

71 Arts. 121 y 148 TFUE, art. 9.2 del Reglamento (CE) 1466/97, y art. 6 del Reglamento (CE) 1176/2011.
} 
líticas de empleo, por lo que resulta imposible discernir los límites entre la coordinación económica y la de empleo. Es más, un alto porcentaje de las recomendaciones de contenido social o de empleo tienen base legal explícita en los mecanismos del PEC o en el procedimiento de desequilibrios macroeconómicos, situándose así claramente en el marco de la coordinación de las políticas económicas ${ }^{72}$.

Esta fusión de los resultados de los diversos procesos de coordinación en las recomendaciones específicas tiene una consecuencia relevante, y es que las recomendaciones sobre cuestiones sociales y de empleo adquieren en el Semestre Europeo un grado de coercitividad del que carecerían si hubiesen sido dictadas en el marco de sus respectivas competencias de coordinación. Hay que tener presente que el art. $121 \mathrm{TFUE}$, en el que se basan el procedimiento de vigilancia multilateral y el de prevención de los desequilibrios macroeconómicos, faculta a la Comisión a dirigir advertencias políticas a los Estados que no cumplan las orientaciones o pongan en peligro la Unión Económica y Monetaria ${ }^{73}$. Y además, si no se cumplen convenientemente las recomendaciones o advertencias, puede adoptarse la decisión de iniciar un procedimiento corrector de los desequilibrios macroeconómicos excesivos, o bien un procedimiento de déficit excesivo, ambos respaldados por multas, sanciones y depósitos ${ }^{74}$.

Por otro lado, la Estrategia Europa 2020 ya avanzaba el deseo de "contar con objetivos claros y referencias transparentes" para obtener mejores resultados en la coordinación ${ }^{75}$. Incluso indicaba que las recomendaciones debían ser suficientemente precisas e incorporar plazos para su realización, lo que ha comenzado a hacerse en los últimos ciclos. Y sin duda las actuales recomendaciones son mucho más explícitas que las adoptadas bajo la Estrategia de Lisboa. Todo ello implica una actuación más incisiva en el ámbito social y de empleo, con encargos concretos para los Estados que acortan el margen de maniobra de los parlamentos nacionales y ponen el acento en su cumplimiento ${ }^{76}$.

72 Sonia BEKKER y Saskia KLOSSE, «The Changing Legal Context of Employment Policy Coordination. How do Social Policy Issues Fare after the Crisis?», European Labour Law Journal, núm. 5, 2014, pp. 12, 13, 16 y ZEITLIN y VANHERCKE, op. cit., nota 35, p. 32. Art. 2.bis.3 del Reglamento (CE) 1466/97 y art. 7.2 del Reglamento (UE) $1176 / 2011$.

74 DE LA PORTE y HEINS, op. cit., nota 14, pp.166-170.

75 Comunicación de la Comisión, «Europa 2020...», op. cit., nota 12, apdo. 5.

76 Los Comités de Empleo y Protección Social han criticado esta circunstancia, solicitando que las Recomendaciones sean más generales, de modo que dejen a los Estados mayor espacio para diseñar las respuestas políticas más adecuadas a 


\section{B. El renovado papel de los fondos estructurales en el Semestre Europeo}

El deseo de reforzar el cumplimiento de las recomendaciones ha llevado a un replanteamiento de la función de los fondos estructurales y de inversión europeos $^{77}$. Durante la etapa de la Estrategia de Lisboa los fondos se habían vinculado a los objetivos temáticos enunciados en las directrices para las políticas de empleo, promoviendo su consecución práctica. Pero a partir de la Estrategia Europa 2020 se ha dado un paso más al vincularse los fondos no solo con sus objetivos temáticos ${ }^{78}$, sino también con los resultados del Semestre Europeo $y$, en términos amplios, con las herramientas de la gobernanza económica ${ }^{79}$. En este sentido, los acuerdos de asociación deberán exponer la relación entre las necesidades de desarrollo y potencial de crecimiento respecto a los que se solicitan las ayudas con el Programa Nacional de Reformas presentado por el Estado en cuestión en el marco del Semestre Europeo, y con las recomendaciones específicas por país dictadas sobre la base de los arts. 121.1 y 148.4 TFUE. La decisión de la Comisión de aprobar el acuerdo de asociación depende de una evaluación previa de su coherencia con los citados instrumentos ${ }^{80}$. Pero además, tras la aprobación del acuerdo de asociación, la Comisión podrá solicitar al Estado beneficiario la revisión y modificación del mismo y de los programas pertinentes cuando sea necesario para contribuir a la aplicación de recomendaciones del Consejo dictadas conforme a los arts. 121.1 y 148.4 TFUE, o al art. 8 del Reglamento (UE) 1176/2011, en el curso de un procedimiento de corrección de desequilibrios macroeconómicos excesivos. Si el Estado no adopta medidas eficaces, la Comisión podrá proponer al Consejo la suspensión parcial de los pagos de los programas afectados, que podrá llegar a ser total en caso de que el

sus circunstancias y a sus tradiciones jurídicas (Employment Comittee and Social Protection Committee, "Joint EMCO-SPC opinion on the mid-term review ...", op. cit., nota 18, apdo. 24). Sin embargo, el deseo de que las recomendaciones fuesen más precisas e incluyesen plazos para su cumplimiento ya fue expresado en la Comunicación de la Comisión, «Europa 2020...», op. cit., nota 12, apdo. 5.2. ARMSTRONG, «EU Social Policy...», op. cit., nota 50, pp. 293, 294. Apdo. 3.2 de la Estrategia.

Véase el art. 1 y el Anexo I del Reglamento (UE) 1303/2013 del Parlamento Europeo y del Consejo, de 17 de diciembre de 2013, por el que se establecen disposiciones comunes relativas al Fondo Europeo de Desarrollo Regional, al Fondo Social Europeo, al Fondo de Cohesión, al Fondo Europeo Agrícola de Desarrollo Rural y al Fondo Europeo Marítimo y de la Pesca, y por el que se establecen disposiciones generales relativas al Fondo Europeo de Desarrollo Regional, al Fondo Social Europeo, al Fondo de Cohesión y al Fondo Europeo Marítimo y de la Pesca, y se deroga el Reglamento (CE) 1083/2006 del Consejo (DO L 347, de 20 de diciembre de 2013, p. 320).

Arts. 15.1.a) i) y 16 del Reglamento (UE) 1303/2013. 
Estado continúe sin adoptar las medidas necesarias. Se prevén medidas similares respecto de los Estados incursos en procedimientos de déficit excesivo o que hayan solicitado ayuda financiera ${ }^{81}$.

A través de esta profunda remodelación de la regulación de los fondos estructurales y de inversión europeos, se establece una relación de condicionalidad entre los mismos y las recomendaciones específicas por país que cierran el ciclo del Semestre Europeo. De este modo, se introduce un nuevo elemento de presión para garantizar el cumplimiento de las recomendaciones dirigidas a los Estados que se benefician de tales fondos. La presencia de este factor de presión más allá del peer review previsto en el Tratado de Funcionamiento evidencia una vez más una reorientación de la coordinación de las políticas sociales y de empleo desde el consenso político en torno a ciertos objetivos generales, hacia el cumplimiento de indicaciones más concretas ${ }^{82}$.

\section{Una coordinación menos participativa e integradora}

El proceso de gobernanza que se lleva a cabo a través del Semestre Europeo no tiene el carácter participativo e integrador propio del MAC que se desarrolló en la Estrategia Europea de Empleo o en el marco de la política social. El origen de esta circunstancia se sitúa ya en el Tratado de Funcionamiento, pues mientras la descripción de los procesos de coordinación de las políticas económicas no contiene ninguna referencia a la participación de los agentes sociales y atribuye al Parlamento Europeo funciones meramente informativas, los Títulos de Empleo y de Política Social involucran expresamente a los interlocutores sociales en los procesos de coordinación ${ }^{83}$.

La nueva redacción del art. 2.bis.4 del Reglamento 1466/97 deja traslucir la ambigüedad del Semestre Europeo por lo que a la participación se refiere. Mientras la coordinación de las políticas económicas y de empleo bajo las OGPE sigue estando liderada por el Consejo y la Comisión, el Parlamento Europeo asume un papel secundario, limitado a un difuso «diálogo económico", que se enuncia como una facultad potestativa del propio Parlamento y consiste en recibir información o en debatir con el presidente del Consejo y/o la Comisión los principales aspectos y resultados del proceso de coordinación $^{84}$. Así las cosas, ni el diálogo económico es parte imprescindible del

\footnotetext{
81 Art. 23 del Reglamento (UE) 1303/2013.

82 ZEITLIN y VANHERCKE, op. cit., nota 35, pp. 56-58.

83 Arts. 148.2 y 150 TFUE respecto de la política de empleo, y art. 152 TFUE respecto de las políticas sociales.

84 La escasa implicación del Parlamento Europeo en el MAC, con el riesgo que ello supone para la legitimidad de los resultados del mismo, ha sido uno de los puntos débiles de este método desde sus orígenes (véase DE LA ROSA, op. cit., nota 8,
} 
Semestre Europeo, ni el Parlamento Europeo asume a través de él funciones decisivas o de orientación política ${ }^{85}$.

Además, la consulta en el marco del Semestre Europeo de los Comités Económico y Financiero, de Política Económica, de Empleo y de Protección Social, se sujeta a la incierta expresión «si procede». Esta cautela contrasta con la decisión con que el art. 148 TFUE ordena al Consejo consultar al Comité de Empleo antes de elaborar las orientaciones de las políticas de empleo para los Estados miembros, y recibir las opiniones de dicho Comité de forma previa al examen de los Planes Nacionales de Reforma. De hecho, el Comité de Empleo fue creado por mandato del art. 150 TFUE para participar en la coordinación de las políticas de empleo con las funciones especificadas en dicho precepto y en el art. 148 TFUE, por lo que es preciso contar con su participación en el Semestre Europeo una vez que la coordinación de las políticas de empleo queda incrustada en él.

Por su parte, el Comité de Protección Social fue creado por el art. 160 TFUE para fomentar la cooperación social entre los Estados miembros y la Comisión. Pese a que el Tratado de Funcionamiento no institucionaliza ningún proceso de coordinación de las políticas sociales y esta competencia no forma parte del Semestre Europeo, el hecho de que la Estrategia Europa 2020 formule una iniciativa emblemática relacionada con la protección social permite concluir que este Comité debería participar en el Semestre Europeo con las atribuciones que describe el art. 160 TFUE.

Aunque el Reglamento 1466/97 no asegura la participación de los Comités en el Semestre Europeo, en la práctica los cuatro han tomado parte regularmente en los ciclos desarrollados hasta ahora ${ }^{86}$, si bien con distinto peso político, pues es evidente que el desarrollo de la Estrategia Europa 2020 en el seno del Semestre Europeo recae en mayor medida sobre los dos Comités económicos, frente a las funciones asumidas por los Comités de Empleo y de Protección Social ${ }^{87}$. En todo

pp. 386-406). El diseño institucional del Semestre Europeo no solo no le pone remedio, sino que incluso agrava esta circunstancia.

Es más, la escasa capacidad de actuación que le concede el actual art. 2 bis ter del Reglamento 1466/97 proviene de las enmiendas que el propio Parlamento pudo hacer valer mediante su función de colegislador en la elaboración del Reglamento (UE) 1175/2011. Véase al respecto FASONE, op. cit., nota 27, pp. 169-171.

Una descripción detallada del papel desenvuelto por ambos Comités entre 2011 y 2014 puede verse en ZEITLIN y VANHERCKE, op. cit., nota 35, pp. 34-51. Sobre las funciones del Comité de Protección Social en el Semestre Europeo, véase, a título ilustrativo, Social Protection Committee, 2015 Work Programme.

Por esa razón ambos Comités han propuesto una serie de ajustes en las funciones que desarrollan en el Semestre Europeo, a fin de mejorar su participación. La propuesta se encuentra en Employment Comittee and Social Protection Committee, "Joint EMCO-SPC opinion on the mid-term review ...", op. cit., nota 18, apdo. 21. Previamente, el CESE ya había propuesto algunas actuaciones para mejorar la 
caso, los ajustes que se siguen produciendo en los instrumentos del Semestre Europeo han incidido recientemente en el régimen jurídico del Comité de Protección Social y del Comité de Empleo ${ }^{88}$. Este último pasa a involucrarse en mayor medida en el proceso de coordinación de las políticas económicas, al ser necesaria su participación en la elaboración de las OGPE. Con ello se pretende garantizar la coherencia de las orientaciones para las políticas de empleo con las OGPE, y propiciar un estrechamiento aún mayor de los procesos de coordinación económica y de empleo. Pero, como viene siendo habitual, ese estrechamiento se alcanza mediante la atracción de los elementos de coordinación de las políticas de empleo al ámbito de la coordinación económica.

En cuanto a los interlocutores sociales, su participación en el Semestre Europeo se canaliza fundamentalmente a través de los Comités de Empleo y Protección social, y de la Cumbre Social Tripartita, cuyo papel dentro del Semestre Europeo también se está tratando de reforzar ${ }^{89}$. Pero de momento su presencia es muy secundaria y su capacidad decisoria nula ${ }^{90}$. Esta situación contradice el espíritu de pluralidad subjetiva al que aspiraba el MAC social y de empleo en sus orígenes. Una fuerte base de concertación social no solo se estimaba idónea por la naturaleza de los asuntos tratados, sino también por la necesidad de dar continuidad a las tradiciones de diálogo social propias de la mayor parte de los Estados miembros. Pero la insuficiente participación de los agentes sociales en el Semestre Europeo es todavía más grave si se tiene en cuenta que algunas de las recomendaciones que el Consejo ha adoptado insistentemente en los últimos años se refieren a los sistemas de determinación salarial, materia que en la mayoría de los Estados forma parte de las atribuciones de la negociación colectiva. De esta forma los Estados asumen compromisos en ámbitos en los que no tienen facultades normativas directas, quedando fuera del proceso de coordinación política quienes sí poseen tales poderes. Ante la gravedad de la situación, el Comité Económico y Social Europeo ha solicitado una mayor participación de los interlocutores sociales y la sociedad civil organizada en diferentes fases del

participación en su «Opinion on 'Strengthening the participatory processes and the involvement of local authorities, NGOs and the social partners in the implementation of Europe 2020' (exploratory opinion)» (DO C 299, 4 de octubre de 2012, p. 1). Decisión (UE) 2015/773 del Consejo, de 11 de mayo de 2015, por la que se crea el Comité de Protección Social y se deroga la Decisión 2004/689/CE (DO L 121, de 14 de mayo de 2015, p. 16) y Decisión (UE) 2015/772 del Consejo, de 11 de mayo de 2015, por la que se crea el Comité de Empleo y se deroga la Decisión 2000/98/ CE (DO L 121, de 14 de mayo de 2015, p. 12).

89 Dictamen del Comité Económico y Social Europeo sobre «La estructura y organización del diálogo social en el contexto de una auténtica Unión Económica y Monetaria» (DO C 458, 19 de diciembre de 2014, p. 1). ZEITLIN y VANHERCKE, op. cit., nota 35, pp. 54. 
Semestre Europeo ${ }^{91}$. Las bases legales para reclamar mayor presencia de los interlocutores sociales se encuentran en una lectura conjunta de la cláusula social horizontal del art. 9 TFUE y del art. 152 TFUE. La consecución de los objetivos mencionados en dicha cláusula, entre los que figuran la promoción de un alto nivel de empleo y la lucha contra la exclusión social, no puede entenderse sin la implicación de los agentes sociales que pretende garantizar el art. 152 TFUE $^{92}$. Con independencia de la ubicación de este precepto en el Título de la Política Social, el hecho de que los procedimientos de gobernanza económica afecten directamente a aspectos sociales debería ser suficiente para justificar su aplicación en este contexto ${ }^{93}$.

Por último, otra circunstancia que desvirtúa el MAC es la estricta sincronización instaurada por el Semestre Europeo. Los plazos previstos para cada fase son rígidos y cortos en relación con la cantidad de trabajo que han de desarrollar los Comités, y ello dificulta que se lleve a cabo con eficacia la vigilancia multilateral entre Estados, la deliberación de todos los participantes en el proceso y la búsqueda de las mejores prácticas ${ }^{94}$. Esta premura pone en peligro la propia esencia del método de coordinación, que podría quedar reducido a una sucesión formal de fases y consultas que encubren un sistema de decisión mucho más imperativo.

$91 \quad$ Dictamen del Comité Económico y Social Europeo sobre la Comunicación de la Comisión al Parlamento Europeo, al Consejo Europeo, al Consejo, al Banco Central Europeo, al Comité Económico y Social Europeo, al Comité de las Regiones y al Banco Europeo de Inversiones, «Medidas en favor de la estabilidad, el crecimiento y el empleo" (DO C 44, 15 de febrero de 2013, p. 153).

92 Filip DORSSEMONT, «Collective Action Against Austerity Measures», y Mélanie SCHMITT, «Evaluation of EU Responses to the Crisis with Reference to Primary Legislation (European Union Treaties and Charter of Fundamental Rights)», ambos en Niklas BRUUN, Klaus LÖRCHER e Isabelle SCHÖMANN (eds.), The Economic and Financial Crisis and Collective Labour Law in Europe, Hart Publishing, Oxford y Portland, 2014, pp. 155 y 206-209, respectivamente.

93 Bruno VENEZIANI, «The Role of the Social Partners in the Lisbon Treaty», en BRUUN, LÖRCHER y SCHÖMANN (eds.), The Lisbon Treaty..., op. cit., nota 5, p. 161.

94 Esta situación ha sido denunciada por los Comités de Empleo y de Protección Social, que han solicitado la revisión de ciertos aspectos del calendario del Semestre Europeo (Employment Comittee and Social Protection Committee, «Joint EMCO-SPC opinion on the mid-term review...», op. cit., nota 18, apdos. 22 y 27, y Employment Committee, «EMCO Review of the 2013 European Semester: Ways forward», 13907/13, 3.10.2013, apdo. 2). En el mismo sentido véase el Dictamen del Comité Económico y Social Europeo sobre la Comunicación de la Comisión al Parlamento Europeo, al Consejo Europeo, al Consejo, al Banco Central Europeo, al Comité Económico y Social Europeo, al Comité de las Regiones y al Banco Europeo de Inversiones, «Medidas en favor...», op. cit., nota 90, apdo. 5.2. Véase también ZEITLIN y VANHERCKE, op. cit., nota 35, p. 61. 


\section{REFLEXIONES CONCLUSIVAS}

Los acontecimientos relatados en las páginas anteriores evidencian una serie de cambios profundos en el papel que juegan las políticas sociales y de empleo en el proceso de integración. Dichos cambios se hacen presentes, por un lado, en la definición de las competencias de coordinación y sus interrelaciones $y$, por otro lado, en las fuentes idóneas para impulsar el proceso de integración.

Por lo que se refiere a las competencias de coordinación, la crisis económica ha puesto de manifiesto la estrecha interconexión entre las áreas económica, social y de empleo, y la imposibilidad de intervenir de manera separada en cada una de ellas en un escenario que tiende hacia un progresivo estrechamiento de las políticas macroeconómicas y fiscales. El desarrollo exacerbado de la competencia de coordinación de las políticas económicas ha generado una insoportable fuerza centrípeta sobre la coordinación de las políticas sociales y de empleo, cuyo diseño normativo ha sido siempre más frágil. En consecuencia, estas competencias han quedado absorbidas en el marco de coordinación económica, perdiendo la autonomía de la que habían disfrutado durante la Estrategia de Lisboa.

Todo ello implica una extralimitación en el uso de la competencia de coordinación de las políticas económicas tanto en sentido horizontal, vulnerando la delimitación entre las diversas competencias de coordinación del art. 5 TFUE, como en sentido vertical, pues la mayor intensidad de la competencia de coordinación de las políticas económicas altera el grado de cesión de soberanía estatal en los ámbitos sociales y de empleo ${ }^{95}$.

Ahora bien, puesto que el proceso de reforma de la gobernanza económica europea no puede darse por concluido, la situación actual plantea diversos interrogantes en torno al futuro de las competencias de coordinación. Si la Unión Económica avanza, como se pretende, hacia mayores niveles de centralización de las políticas económicas y presupuestarias ${ }^{96}$, es probable que haya que reformular las competencias de coordinación del art. 5 TFUE como una única macrocompetencia de guía política, supervisión, corrección y ejecución que aglutine las acciones llevadas a cabo en el plano económico, social y de empleo. En tal caso, el reto consistiría en integrar las actuaciones propias de estas tres áreas de forma equilibrada, sin que la lógica y objetivos de una de ellas condujesen a la anulación de las otras, como ha sucedido hasta ahora.

Pero tal reto no puede abordarse atendiendo únicamente a la sempiterna confrontación entre los aspectos económicos y sociales de la Unión Europea, sino

\footnotetext{
95 Roberto CISOTTA, «What Role for the European Commission in the New Governance of the Economic and Monetary Union?», IAI Working Papers, 13/24, 2013, p. 6.

96 Realizar la Unión Económica y Monetaria. Informe de Jean-Claude Juncker en estrecha cooperación con Donald Tusk, Jeroen Dijsselbloem, Mario Draghi y Martin Schulz, 22 de junio de 2015.
} 
que habría que buscar las claves para su resolución en un proyecto político de mayor envergadura, capaz de establecer prioridades y equilibrios entre todos los elementos que conforman la integración europea ${ }^{97}$. A falta de una clara orientación hacia una Unión Política, la difusa amalgama de valores y objetivos plasmada en el Derecho originario debería servir de guía para evitar el definitivo naufragio de las competencias sociales.

La segunda conclusión que se extrae del presente análisis es que la irrupción de las técnicas de la gobernanza económica europea, y su incidencia en el plano sociolaboral, ha culminado una alteración en el sistema de fuentes del Derecho social europeo cuyos primeros síntomas comenzaron a percibirse en torno al inicio del siglo, justo con el arranque de los procesos de coordinación de las políticas sociales. Puede afirmarse ya sin dudas que las fuentes de soft law - hoy asociadas a la gobernanza económica europea - han desplazado el uso del método comunitario en el ámbito de la política social ${ }^{98}$. Sin embargo, no es éste un fenómeno aislado dentro del Derecho de la Unión Europea, sino que se trata de una manifestación más de la actual tendencia del proceso de integración, dispuesto a abandonar progresivamente el lenguaje de los derechos en beneficio de las competencias de supervisión y control, ejercitadas mediante órganos despolitizados e instrumentos de soft law $w^{99}$.

Desde que en 2011 tuvo lugar el primer ciclo del Semestre Europeo, la intervención sobre los sistemas jurídico-laborales de los Estados miembros ha sido muy intensa. Las ventajas que presenta el uso de estas fuentes poco ortodoxas frente al método comunitario son evidentes. Se trata de instrumentos dotados de una gran inmediatez, tanto en su elaboración como en su ejecución, capaces de influir profundamente en los ordenamientos de los Estados, que escapan al control del Tribunal de Justicia ${ }^{100}$ y que permiten un uso flexible de las bases competenciales en materia económica, social y de empleo ${ }^{101}$.

$97 \quad$ Frank HENDRICKX, «Completing Economic and Social Integration: Towards Labour Law for the United States of Europe», en Nicola COUNTOURIS y Mark FREEDLAND (eds.), Resocialising Europe in a Time of Crisis, Cambridge University Press, 2013, p. 80. ARMSTRONG, «EU Social Policy...», op. cit., nota 50, pp. 292, 294, 295. Takis TRIDIMAS, «Competence after Lisbon. The Elusive Search for Bright Lines», Diamond ASHIAGBOR, Nicola COUNTOURIS e Ioannis LIANOS (eds.), The European Union after the Treaty of Lisbon, Cambridge University Press, 2012, p. 77. A pesar de que ya se han planteado ante el Tribunal de Justicia algunos casos relacionados con el impacto de Memorandos de Entendimiento o instrumentos de la gobernanza económica ordinaria en la esfera interna, ninguno de ellos ha logrado prosperar. Véase, por todos, la sentencia del Tribunal de Justicia Nisttahuz Poclava, C-117/14, ECLI:EU:C:2015:60.

101 En relación con los rescates, véanse las apreciaciones de Claire KILPATRICK, "Are the Bailouts Immune to EU Social Challenge Because They Are Not EU Law?», European Constitutional Law Review, núm. 10, 2014, p. 393. 
Frente a la pujanza de estas fuentes contrasta la decadencia de la actividad legislativa de la Unión Europea en materia social, que pone de manifiesto la falta de interés político por avanzar en la protección de ciertos derechos laborales poco compatibles con las tendencias económicas dominantes, así como la dificultad de alcanzar consensos en materias de política social ${ }^{102}$. Por su parte, la integración de la Carta de Derechos Fundamentales en el Derecho originario ha contribuido a apuntalar el discurso de los derechos en la Unión Europea, pero la necesaria concurrencia de Derecho derivado para desencadenar su aplicabilidad minimiza la eficacia de los derechos sociales fundamentales, pues, como se ha indicado, las competencias legislativas en materia social no han sido plenamente ejercitadas ${ }^{103}$.

Con todo, el aspecto más grave de la proliferación de fuentes de soft law en materia sociolaboral al amparo del Semestre Europeo es que este fenómeno se haya desarrollado de espaldas al acervo social europeo, subordinándose a la política económica y sus intereses sin ningún contrapeso ${ }^{104}$. Ahora bien, el evidente fracaso de las políticas económicas impulsadas por la Unión Europea en los últimos años para reducir las desigualdades sociales y laborales evidencia la urgente necesidad de revitalizar el papel corrector de las políticas sociales y de empleo frente a las dinámicas económicas ${ }^{105}$.

Por consiguiente, el gran desafío que afronta hoy la Unión Europea en materia de política social consiste en reconciliar y cohesionar las fuentes de Derecho duro ya existentes con las fuentes de Derecho blando, a fin de recuperar el precario equilibrio de valores y objetivos económicos y sociales que a golpe de complejas reformas ha intentado plasmarse en el Derecho originario.

Hay algunos signos alentadores que revelan el deseo de corregir la orientación excesivamente economicista de la coordinación desarrollada durante

102 Catherine BARNARD, «A Proportionate Response to Proportionality in the Field of Collective Action», ELRev, núm. 2, 2012, pp. 117-135.

103 Angela WARD, «Article 51», en Steve PEERS, Tamara HERVEY, Jeff KENNER y Angela WARD (eds.), The EU Charter of Fundamental Rights. A Commentary, Hart Publishing, Oxford, 2014, pp. 1413-1454 y Giovanni ORLANDINI, «Los derechos fundamentales de los trabajadores en la jurisprudencia del Tribunal de Justicia de la Unión Europea», Revista de Derecho Social, núm. 69, 2015, pp. 57-77. Simon DEAKIN, "The Lisbon Treaty, the Viking and Laval Judgments and the Financial Crisis: In Search of New Foundations for Europe's 'Social Market Economy'", en BRUUN, LÖRCHER y SCHÖMANN (eds.), The Lisbon Treaty..., op. cit., nota 5, p. 32.

105 Janine LESCHKE, Sotiria THEODOROPOULOU y Andrew WATT, «Towards 'Europe 2020'? Austerity and New Economic Governance in the EU», en Steffen LEHNDORFF (ed.), Divisive integration. The Triumph of Failed Ideas in Europe Revisited, ETUI, Brussels, 2015, pp. 295-329. 
los primeros años de la gobernanza económica europea, que mereció duras críticas $^{106}$. Sin embargo, sería preciso adoptar enfoques más ambiciosos, estableciendo por ejemplo mecanismos de impacto previos, similares a los que existen respecto de las competencias legislativas, para verificar la adecuación del Derecho blando y efímero que nace en el Semestre Europeo con el acervo comunitario ${ }^{107}$. En este sentido, se podría atribuir algún tipo de función supervisora al Tribunal de Justicia o a la Agencia de los Derechos Fundamentales de la Unión Europea.

Pero, además, es importante volver a impulsar el ejercicio de las competencias legislativas en materia social, al menos para dotar de operatividad a los derechos fundamentales recogidos en el Título IV de la Carta de Derechos Fundamentales de la Unión Europea, y evitar que sigan siendo papel mojado.

Solo recuperando la voz propia de las políticas sociales y de empleo, respaldándolas con normas de Derecho duro, e integrándolas como procesos autónomos en el Semestre Europeo a fin de fomentar un diálogo con las políticas económicas, el proyecto de integración europea podrá volver a aproximarse al ideal de economía social de mercado que se anuncia en el umbral del Derecho originario.

106 La primera señal significativa de cambio vino dada por la Comunicación de la Comisión al Parlamento Europeo y al Consejo, «Reforzar la dimensión social de la Unión Económica y Monetaria», $\operatorname{COM(2013)~} 690$ final, 2.10.2013. Las recomendaciones específicas por país de 2014 incluyeron más cláusulas de salvaguarda en temas sociales y de empleo. Y en 2015 hay que traer a colación la elaboración de unas Directrices integradas más equilibradas, así como la modificación del régimen jurídico de los Comités de Protección Social y de Empleo a fin de definir con mayor exactitud su rol en el Semestre Europeo.

107 Véanse las variadas propuestas lanzadas por Catherine BARNARD, «EU Employment Law and the European Social Model: The Past, the Present and the Future», Current Legal Problems, vol. 67, núm.1, 2014, pp. 225-237 y por Mark DAWSON, New Governance and the Transformation of European Law. Coordinating EU Social Law and Policy, Cambridge University Press, 2011, pp. 300-310. 